\title{
The effect of diet on the compositions of the triglycerides and unesterified fatty acids isolated from the plasma, liver and adipose tissues of rabbits
}

\author{
By J. H. MOORE AND D. L. WILLIAMS \\ National Institute for Research in Dairying, Shinfield, Reading \\ (Received I I August 1965-Accepted 8 October 1965)
}

\begin{abstract}
1. Groups of male rabbits (ten to thirteen per group survived) were given ad lib. a diet consisting of 80 parts of a low-fat basal diet to which were added: for group $r, 20$ parts maize oil; for group 2, 20 parts butterfat; for group 3, 10 parts maize oil and and 10 parts butterfat; for group 4, 0.47 parts maize oil and 43.1 parts wheat starch; and for group 5, I0.2 parts maize oil and $2 \mathbf{r} \cdot 6$ parts wheat starch. The animals in group 6 were given an ordinary commercial rabbit diet. 2 . The rabbits were given the various diets for $3^{8}$ weeks, after which a sample of blood was taken. The rabbits were then killed and the liver and a sample of perinephric adipose tissue were removed from each animal. The plasma, liver and adipose tissue lipids were fractionated on columns of Florisil and the fatty acid compositions of the triglyceride and unesterified fatty acid fractions were determined by gas-liquid chromatography. 3. The effects of the different diets on the composition of the unesterified fatty acids in the plasma were very similar to the effects of the diets on the fatty acid composition of the plasma triglycerides, but in the plasma unesterified fatty acids the concentration of stearic acid was consistently higher and the concentration of linoleic acid was consistently lower than in the plasma triglycerides. 4 . There appeared to be a positive rectilinear relationship between the concentration of stearic acid in the plasma triglycerides and the concentration of triglycerides in the plasma. 5. In the triglycerides of the plasma, the concentrations of palmitic and stearic acids were consistently greater and the concentration of linoleic acid was consistently less than the corresponding concentrations of these fatty acids in the triglycerides of the adipose tissues. In the two groups of rabbits given low-fat diets the fatty acid composition of the liver triglycerides was almost identical with that of the plasma triglycerides. 6 . In each of the six groups of rabbits the composition of the unesterified fatty acids in the plasma was identical with that of the unesterified fatty acids in the adipose tissues. In the unesterified fatty acids of the liver the concentrations of linoleic and arachidonic acids were consistently greater and the concentrations of myristic, palmitic and palmitoleic acids were consistently less than the corresponding concentrations of these acids in the unesterified fatty acids of the plasma and adipose tissues. 7. The results of this investigation are discussed in the light of recent concepts on the metabolic relationships between the unesterified fatty acids and triglycerides of the liver, plasma and adipose tissues.
\end{abstract}

In previous publications Moore \& Williams (1964c, 1965) have described the effects of diet on the fatty acid compositions of the phospholipids and cholesterol esters in the plasma of the rabbit. These studies have now been extended by a detailed investigation of the fatty acid compositions of the triglyceride and unesterified fatty acid fractions isolated from the plasma samples obtained from the rabbits of Expt 2 described by Moore \& Williams (1964a). The results are now reported together with a discussion of the metabolic relationship between the triglycerides and unesterified fatty acids of the plasma, liver and adipose tissues of the rabbit. 


\section{EXPERIMENT AL}

Rabbits, diets and experimental procedure. The experimental procedures have been described in detail previously (Moore \&Williams, $1964 a, b$ ) and will only be summarized.

Eighty-four male New Zealand White $\times$ Lop Ear rabbits, 4 months of age at the beginning of the experiment, were divided into six groups of fourteen each. The rabbits were housed in individual cages and were given food and water ad lib. To 8o parts of a semi-purified, low-fat basal diet (Moore \& Williams, I964a) were added: for group I, 20 parts maize oil; for group 2, 20 parts butterfat; for group 3, ro parts maize oil and ro parts butterfat; for group 4, 0.47 parts maize oil and 43.I parts wheat starch; and for group 5, 10.2 parts maize oil and 21.6 parts wheat starch. The animals in group 6 were given an ordinary commercial rabbit diet. The various diets were given to the six groups of rabbits for 38 weeks, after which samples of blood were taken from the marginal ear veins. The rabbits were then killed, and from each the liver and a sample of perinephric adipose tissue were removed.

Extraction of lipids and methods of analysis. The lipids were extracted from the samples of plasma by the method of Nelson \& Freeman (1959) and from the livers and samples of adipose tissues by the method of Folch, Lees \& Stanley (I957). The lipid extracts obtained from the plasma of each rabbit were analysed individually, whereas those obtained from the livers of each group of rabbits were pooled before analysis, as were the lipid extracts obtained from the samples of adipose tissues. Portions of the lipid extracts were chromatographed on columns of Florisil (Koch-Light Laboratories Ltd, Colnbrook, Bucks) according to the method of Carroll (196r). The triglycerides were eluted with hexane-diethyl ether $(95: 5, \mathrm{v} / \mathrm{v})$ and the unesterified fatty acids with diethyl ether-acetic acid $(96: 4, v / v)$. The nature of each fraction was checked by thin-layer chromatography as described previously (Moore \& Williams, $1964 b$ ). Glyceride glycerol was determined by the method of Moore (1962) and unesterified fatty acids by the titration procedure of Albrink (1959). The compositions of the fatty acids present in the triglyceride and unesterified fatty acid fractions were determined by gas-liquid chromatography (Moore \& Williams, r963, r964d).

Statistical analysis. From a preliminary examination of the results for the fatty acids of the plasma triglycerides and unesterified fatty acids, it was evident that the standard deviation between animals within a diet group tended to be proportional to the diet group mean. Consequently, all observational values were transformed to logarithms in order to reduce heterogeneity among the within-group variances. The tests of significance summarized in Tables 2 and 3 refer to differences between mean logarithmic values for each diet group. These values are presented in Tables 2 and 3 by their antilogarithms which are the geometric means for each diet. Arithmetic means of the untransformed values are also given; they agree roughly with the geometric means which are invariably smaller. The tests of significance are based on the multiplerange test (Duncan, I955) as modified for unequal numbers of replications (Kramer, I956). The mean values shown in Tables 2 and 3 for each group differ significantly $(P<0.01)$ except when they share a common underlining. Thus, with the mean concentrations of linoleic acid (18:2) in Table 2 as examples, the value for group $\mathrm{I}$ is 
not significantly different from the values for groups 5 and 6 but is significantly greater than the values for groups 2, 3 and 4 . Similarly, the value for group 4 is not significantly different from the value for group 2 but is significantly lower than the value for group 3 .

\section{RESULTS}

The fatty acid compositions of the diets given to the six groups of rabbits have been reported by Moore \& Williams ( $1964 c)$. Certain of the animals died during the experiment, and the number of rabbits in each group at the end of the experiment together with the concentrations of triglycerides and unesterified fatty acids in the plasma of the rabbits are given in Table $\mathbf{I}$. The proportions of the major fatty acids present in the

Table I. Number of rabbits in each group at the end of the experiment and concentrations of triglycerides (calculated as triolein) and unesterified fatty acids (calculated as oleic acid) in the plasma of the rabbits

No. of rabbits

Triglycerides* (mg/100 ml plasma)

Unesterified fatty acids* (mg/roo ml plasma)

\begin{tabular}{|c|c|c|c|c|c|}
\hline $\begin{array}{c}\text { Group I } \\
(20 \% \\
\text { maize- } \\
\text { oil } \\
\text { diet) }\end{array}$ & $\begin{array}{c}\text { Group 2 } \\
\text { (20\% } \\
\text { butterfat } \\
\text { diet) }\end{array}$ & $\begin{array}{c}\text { Group } 3 \\
\text { (10\% } \\
\text { maize- } \\
\text { oil, } \\
\text { I0\% } \\
\text { butterfat } \\
\text { diet) }\end{array}$ & $\begin{array}{c}\text { Group } 4 \\
\text { (low-fat, } \\
\text { high- } \\
\text { starch } \\
\text { diet) }\end{array}$ & $\begin{array}{l}\text { Group } 5 \\
\text { (10\% } \\
\text { maize- } \\
\text { oil, } \\
\text { starch } \\
\text { diet) }\end{array}$ & $\begin{array}{l}\text { Group } 6 \\
\text { (com- } \\
\text { mercial } \\
\text { diet) }\end{array}$ \\
\hline 12 & I3 & I3 & I 2 & 10 & 12 \\
\hline $48 \cdot 3 \pm 7 \cdot 2$ & $69.5 \pm 7 \cdot 6$ & $61 \cdot 5 \pm 3.8$ & $6 x \cdot 1 \pm 6 \cdot x$ & $48 \cdot 5 \pm 5 \cdot 1$ & $50 \cdot 3 \pm 6 \cdot 3$ \\
\hline$I I \cdot 6 \pm I \cdot I$ & $17 \cdot 3 \pm 2 \cdot 0$ & $16 \cdot 8 \pm x \cdot 5$ & $10 \cdot 2 \pm 2 \cdot 0$ & $10.7 \pm 2.0$ & $15.7 \pm 3.0$ \\
\hline
\end{tabular}

plasma triglycerides are given in Table 2 in which (and elsewhere in this paper) the shorthand designation suggested by Farquhar, Insull, Rosen, Stoffel \& Ahrens (1959) is used to denote the various fatty acids. The composition of the fatty acids in the plasma triglycerides of the rabbits given the commercial diet (group 6) was similar to that reported by Swell, Law, Schools \& Treadwell (I96r) for the plasma triglycerides of rabbits also given a commercial diet. The concentrations of myristic and palmitic acids in the plasma triglycerides of the rabbits in group I were significantly lower than the corresponding concentrations of these fatty acids in the plasma triglycerides of the other five groups of rabbits. The relatively high concentrations of myristic acid in the two diets containing butterfat were reflected to some extent by the higher levels of myristic acid in the plasma triglycerides of the rabbits in groups 2 and 3. However, the differences between the concentrations of myristic acid in the plasma triglycerides of the rabbits of groups $3,4,5$ and 6 did not achieve the I\% level of significance. In agreement with the previous findings for the plasma cholesterol esters (Moore \& Williams, I965) the concentration of palmitoleic acid in the plasma triglycerides appeared to vary inversely with the content of total unsaturated fatty acids (i.e. $16: 1+18: 1+18: 2$ ) in the diet. The concentration of stearic acid in the plasma triglycerides of the experimental rabbits did not vary to any great extent with dietary treatment, but the concentration of this saturated acid in the plasma triglycerides of the rabbits in group 2 (given the $20 \%$ butterfat diet) was significantly 
greater than that in the plasma triglycerides of the rabbits in group I (given the $20 \%$ maize-oil diet). Although there were no significant differences in the concentrations of oleic acid in the plasma triglycerides of the rabbits in groups $1,2,3,4$ and 6 , the

\section{Table 2. Fatty acid compositions (weight percentages) of the triglycerides in the plasma of the rabbits on the various dietary treatments}

(Ranking of means and significance of differences by the multiple-range test (Duncan, I955; Kramer, 1956). The mean values differ significantly $(P=0.01)$ except when they share a common underlining)

Average standard error of the mean (66 df), $\log$ units
Group no....

Arithmetic mean

Geometric mean

Mean $\log$

Group no....

Arithmetic mean

Geometric mean

Mean log

Group no....

Arithmetic mean

Geometric mean

Mean $\log$

Group no....

Arithmetic mean Geometric mean Mean log

Group no....

Arithmetic mean

Geometric mean

Mean log

\begin{tabular}{ll}
2 & 3 \\
$6 \cdot 5$ & $4 \cdot 0$ \\
$5 \cdot 6$ & $3 \cdot 6$ \\
0.75 & 0.55 \\
\hline
\end{tabular}

4
$2 \cdot 7$
$2 \cdot 6$
$0 \cdot 41$

14:0

$\begin{array}{lll}6 & 5 & 1 \\ 2 \cdot 6 & 2 \cdot 5 & 1 \cdot 5 \\ 2 \cdot 4 & 2 \cdot 3 & 1 \cdot 1 \\ 0 \cdot 38 & 0 \cdot 37 & 0 \cdot 06\end{array}$

I6:0

$\begin{array}{cccccc}4 & 6 & 5 & 3 & 2 & \text { I } \\ 35 \cdot 6 & 35 \cdot 0 & 33 \cdot 0 & 32 \cdot 8 & 31 \cdot 9 & 20 \cdot 0 \\ 35 \cdot 2 & 34 \cdot 9 & 32 \cdot 5 & 32 \cdot 3 & 30 \cdot 9 & 19 \cdot 4 \\ I \cdot 55 & I \cdot 54 & I \cdot 51 & I \cdot 51 & I \cdot 49 & \end{array}$

\begin{tabular}{llllll} 
I.55 & I.54 & I.5 I & I.5 I & I.49 & I.29 \\
\hline
\end{tabular}

\begin{tabular}{|c|c|c|c|c|c|}
\hline 4.0 & $\begin{array}{c}6 \\
2 \cdot 6\end{array}$ & 2 & $\begin{array}{c}3 \\
2 \cdot 5\end{array}$ & $\begin{array}{c}5 \\
2 \cdot 2\end{array}$ & $\begin{array}{c}\mathbf{T} \\
\mathrm{I} \cdot 6\end{array}$ \\
\hline $5 \cdot 6$ & 3.5 & $2 \cdot 7$ & $\begin{array}{l}4.3 \\
2 \cdot 4\end{array}$ & $2 \cdot 1$ & I. 5 \\
\hline 0.75 & 0.54 & 0.43 & $0.3^{8}$ & 0.33 & O.I7 \\
\hline
\end{tabular}

I $8: 0$

\begin{tabular}{cccccc}
2 & 3 & 4 & 6 & 5 & I \\
$7 \cdot 8$ & $6 \cdot 8$ & $6 \cdot 3$ & $5 \cdot 5$ & $5 \cdot 2$ & $5 \cdot 3$ \\
$7 \cdot 5$ & $6 \cdot 6$ & $5 \cdot 5$ & $5 \cdot 3$ & $5 \cdot 0$ & $4 \cdot 6$ \\
0.88 & 0.82 & 0.74 & $0 \cdot 73$ & 0.70 & 0.66 \\
\hline
\end{tabular}

I 8: I

\begin{tabular}{cccccc}
4 & $\mathrm{I}$ & 2 & 3 & 6 & 5 \\
$33 \cdot 6$ & $29 \cdot 8$ & $28 \cdot 6$ & $28 \cdot 2$ & $27 \cdot 7$ & $25 \cdot 6$ \\
$32 \cdot 9$ & $29 \cdot 7$ & $28 \cdot 1$ & $27 \cdot 9$ & $27 \cdot 3$ & $25 \cdot 5$ \\
$\mathrm{I} \cdot 5 \mathbf{5}$ & $\mathrm{I} \cdot 47$ & $\mathrm{I} \cdot 45$ & $\mathrm{I} \cdot 45$ & $\mathrm{I} \cdot 44$ & $\mathrm{I} \cdot 4 \mathrm{I}$ \\
\hline
\end{tabular}

I 8:2

Group no....

Arithmetic mean

Geometric mean

Mean log

\begin{tabular}{cccccc}
$I$ & 5 & 6 & 3 & 2 & 4 \\
$37 \cdot 8$ & $27 \cdot 4$ & $20 \cdot 8$ & $20 \cdot 5$ & $14 \cdot 4$ & $9 \cdot 9$ \\
$35 \cdot 5$ & $26 \cdot 2$ & $20 \cdot 2$ & $18 \cdot 4$ & $11 \cdot 1$ & $8 \cdot 9$ \\
$\mathrm{I} \cdot 55$ & $\mathrm{I} \cdot 42$ & $1 \cdot 30$ & $1 \cdot 20$ & $1 \cdot 05$ & 0.95 \\
\hline
\end{tabular}

Group no...

Arithmetic mean

Geometric mean

Mean $\log$

\begin{tabular}{rccccc}
\multicolumn{5}{c}{$20: 4$} & \\
2 & 3 & $\mathrm{I}$ & 6 & 5 & 4 \\
$\mathrm{I} \cdot 0$ & 0.8 & 0.8 & 0.8 & 0.8 & 0.5 \\
$\mathrm{I} \cdot 0$ & 0.7 & 0.8 & 0.7 & 0.6 & 0.4 \\
-0.02 & -0.12 & -0.13 & -0.14 & -0.25 & -0.35 \\
\hline
\end{tabular}

$\pm 0.021$

$\pm 0.067$

$\pm 0.027$

$\pm 0.047$

$\pm 0.048$

$\pm 0.063$

$\pm 0.05^{8}$

Group 1, 20\% maize-oil diet; group 2, 20\% butterfat diet; group 3, 10\% maize-oil, 10\% butterfat diet; group 4, low-fat, high-starch diet; group 5, 10\% maize-oil, starch diet; group 6, commercial diet.

The numbers of animals in each group at the end of the experiment are given in Table $I$. 
concentration of oleic acid in the plasma triglycerides of the rabbits in group 5 was significantly less than that in the plasma triglycerides of the rabbits in group 4 . It is clear that the concentration of linoleic acid in the plasma triglycerides was governed

\section{Table 3. Compositions (weight percentages) of the unesterified fatty acids in} the plasma of the rabbits on the various dietary treatments

(Ranking of means and significance of differences by the multiple-range test (Duncan, I 955; Kramer, 1956). The mean values differ significantly $(P=0.01)$ except when they share a common underlining)

Group no.... Arithmetic mean Geometric mean Mean $\log$

Group no.... Arithmetic mean Geometric mean Mean log

Group no... Arithmetic mean Geometric mean Mean $\log$

Group no.... Arithmetic mean Geometric mean Mean $\log$

Group no... Arithmetic mean Geometric mean Mean log

Group no.... Arithmetic mean Geometric mean Mean log

Group no.... Arithmetic mean Geometric mean Mean log

\begin{tabular}{ll}
2 & \\
$5 \cdot 0$ & 4 \\
$4 \cdot 8$ & $4 \cdot 3$ \\
0.68 & $0 \cdot 63$ \\
\hline
\end{tabular}

$\begin{array}{cccc} & 14: 0 & & \\ 5 & 3 & 6 & 4 \\ 4.7 & 4.5 & 3.6 & 3.6 \\ 4.3 & 4.2 & 3.5 & 3.5 \\ 0.63 & 0.62 & 0.55 & 0.55\end{array}$

16:0

\begin{tabular}{ccccccl}
6 & 4 & 5 & 2 & 3 & 1 & \\
$37 \cdot 7$ & $35 \cdot 8$ & $34 \cdot 7$ & $34 \cdot 2$ & $33 \cdot 9$ & $24 \cdot 3$ & \\
$37 \cdot 5$ & $35 \cdot 7$ & $34 \cdot 2$ & $33 \cdot 9$ & $33 \cdot 8$ & $24 \cdot 1$ & \\
$1 \cdot 57$ & $x \cdot 55$ & $I \cdot 53$ & $1 \cdot 53$ & $1 \cdot 53$ & I.38 & $\pm 0 \cdot 017$ \\
\hline
\end{tabular}

I6: I

\begin{tabular}{ll}
4 & 6 \\
$5 \cdot 3$ & $4 \cdot 4$ \\
$5 \cdot 2$ & $4 \cdot 3$ \\
$0 \cdot 72$ & $0 \cdot 63$ \\
\hline
\end{tabular}

5

$\begin{array}{llll}3 \cdot 0 & 2 \cdot 7 & 2 \cdot 7 & 1 \cdot 8\end{array}$

$\begin{array}{llll}2.7 & 2.6 & 2.5 & 1.7\end{array}$

I $8: 0$

\begin{tabular}{|c|c|c|c|c|c|}
\hline 2 & 6 & 3 & 4 & 5 & I \\
\hline 14.9 & $12 \cdot 0$ & I $I \cdot 8$ & $11 \cdot 7$ & II 6 & 10.0 \\
\hline $\begin{array}{l}14 \cdot 2 \\
1 \cdot 15\end{array}$ & $\begin{array}{l}\text { I I.7 } \\
\text { I.07 }\end{array}$ & $\begin{array}{c}\text { I I·5 } \\
\text { I. } 06\end{array}$ & $\begin{array}{l}11 \cdot 2 \\
1 \cdot 05\end{array}$ & $\begin{array}{l}\text { I I'I } \\
\text { I. } 05\end{array}$ & $\begin{array}{l}9.4 \\
0.97\end{array}$ \\
\hline
\end{tabular}

I8: I

\begin{tabular}{ccccccl}
$I$ & 4 & 2 & 3 & 5 & 6 & \\
$30 \cdot 2$ & $29 \cdot 7$ & $29 \cdot 1$ & $26 \cdot 3$ & $23 \cdot 3$ & $22 \cdot 7$ & \\
$30 \cdot 0$ & $29 \cdot 5$ & $28 \cdot 8$ & $26 \cdot 0$ & $22 \cdot 9$ & $22 \cdot 5$ & \\
$I \cdot 48$ & $1 \cdot 47$ & $I \cdot 46$ & $I \cdot 42$ & $I \cdot 36$ & $I \cdot 35$ & $\pm 0 \cdot 019$ \\
\hline
\end{tabular}

$18: 2$

\begin{tabular}{ccccccc}
1 & 5 & 3 & 6 & 2 & 4 & \\
$29 \cdot 8$ & $16 \cdot 3$ & $14 \cdot 3$ & $12 \cdot 6$ & $8 \cdot 5$ & $8 \cdot 0$ & \\
$29 \cdot 3$ & $15 \cdot 1$ & $13 \cdot 8$ & $12 \cdot 3$ & $7 \cdot 7$ & $7 \cdot 6$ & \\
$1 \cdot 47$ & $I \cdot 18$ & $I \cdot 14$ & $I \cdot 09$ & 0.89 & 0.88 & \pm 0.045 \\
\hline
\end{tabular}

\begin{tabular}{ccccccc} 
I & 6 & 20.4 & & & & \\
1.2 & 0.7 & 0.7 & 0.7 & 0.5 & 0.2 & \\
0.9 & 0.6 & 0.6 & 0.5 & 0.4 & 0.2 & \\
-0.05 & -0.19 & -0.26 & -0.27 & -0.43 & -0.70 & $\pm 0.1 I$ \\
\hline
\end{tabular}

Group I, $20 \%$ maize-oil diet; group 2, 20\% butterfat diet; group 3, 10\% maize-oil, 10 \% butterfat diet; group 4, low-fat, high-starch diet; group 5, $10 \%$ maize-oil, starch diet; group 6, commercial diet. The numbers of animals in each group at the end of the experiment are given in Table $I$. 
to some extent by the linoleic acid content of the diet, but it should be noted that, whereas the concentrations of linoleic acid in the plasma triglycerides of the rabbits in groups 3 and 6 were virtually identical, the linoleic acid contents ( $\mathrm{g} / \mathrm{ro0} \mathrm{g}$ diet) of the diets given to these two groups of rabbits were 5.44 and ${ }_{1} .85$ respectively. In addition, the concentration of linoleic acid in the plasma triglycerides of the rabbits in group 2 was not significantly lower than that in the plasma triglycerides of the rabbits in group 3 yet the diet given to the animals in group 2 contained only $0.27 \%$ linoleic acid.

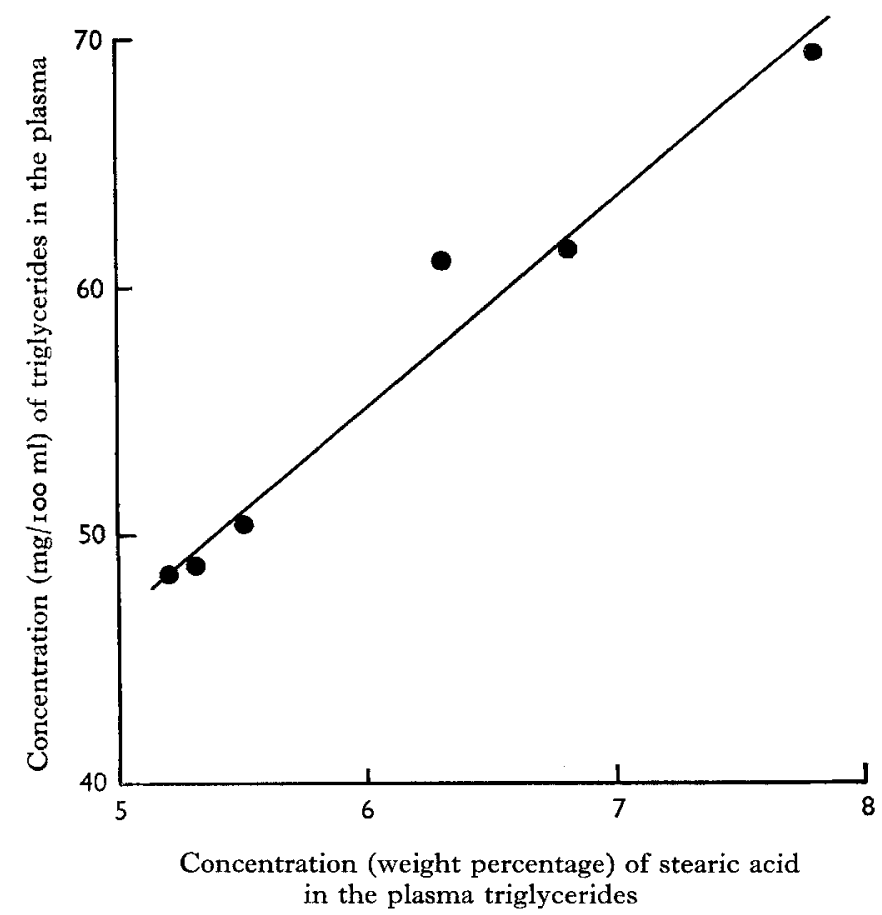

Fig. I. Relationship in the rabbit between the concentration of triglycerides in the plasma $(y)$ and the concentration of stearic acid in the plasma triglycerides $(x)$. Regression equation, $y=4.58+8.45 x^{* * *}$; standard error of slope, \pm 0.792 ; correlation coefficient, $0.983^{* * *}$.$$
* * P<0.001 \text {. }
$$

The compositions of the unesterified fatty acids in the plasma of the rabbits on the various dietary treatments are given in Table 3 . Comparison of these results with those given in Table 2 shows that the effects of the different diets on the compositions of the unesterified fatty acids in the plasma were similar to the effects of the diets on the fatty acid compositions of the plasma triglycerides. Though changes in the fatty acid composition of the plasma triglycerides were reflected to a large extent by the changes in the composition of the plasma unesterified fatty acids, it is important to note that in each group of rabbits the concentration of stearic acid was markedly higher in the plasma unesterified fatty acids than in the plasma triglycerides. On the other hand, the concentration of linoleic acid in the plasma triglycerides was consistently greater than that in the plasma unesterified fatty acids. In the serum of man 


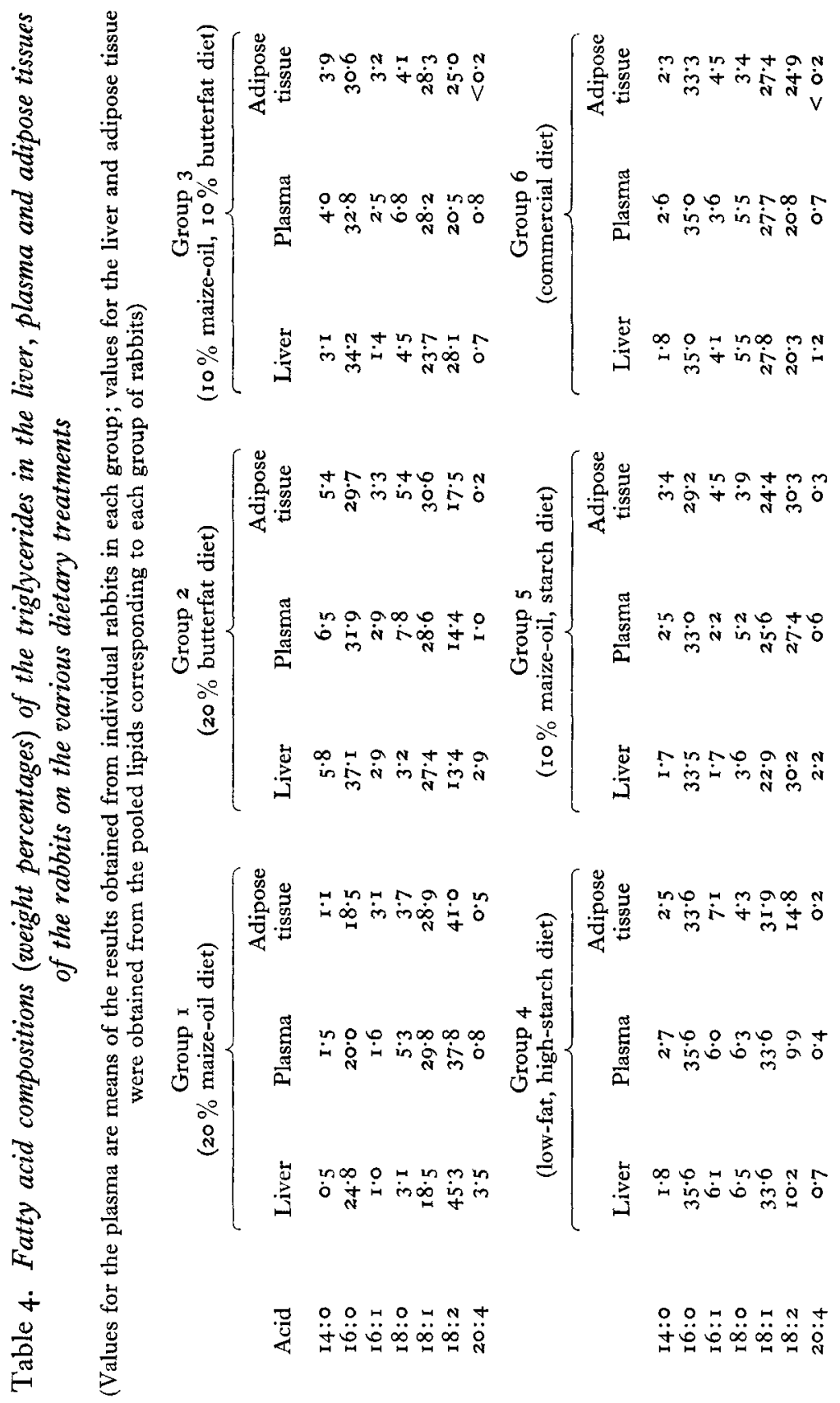


(Hirsch, Farquhar, Ahrens, Peterson \& Stoffel, r 960; Schrade, Biegler \& Böhle, I961) and in the plasma of the rat (Arvidson \& Olivecrona, 1962) it has been reported that the unesterified fatty acid fraction contains considerably higher concentrations of stearic acid but somewhat lower concentrations of both oleic and linoleic acids than does the triglyceride fraction.

Comparison of the results in Tables 3 and $\mathrm{I}$ revealed that the composition of the plasma unesterified fatty acids did not seem to be related in any way to the concentration of the unesterified fatty acids in the plasma. However, there would appear to be a positive rectilinear relationship between the concentration of stearic acid in the plasma triglycerides and the concentration of triglycerides in the plasma (Fig. I).

The fatty acid compositions of the triglycerides isolated from the pooled livers and pooled adipose tissues obtained from each group of rabbits are given in Table 4. To facilitate comparison, the mean fatty acid compositions of the triglycerides in the plasma of each group of rabbits are also given in Table 4. The effects of the different dietary treatments on the fatty acid compositions of the triglycerides of the plasma and adipose tissues were similar. Although there was a broad similarity in fatty acid composition between the triglycerides of the plasma and of the adipose tissues, there were small but consistent differences in the concentrations of certain of the constituent fatty acids. In the triglycerides of the plasma of all six groups of rabbits the concentrations of palmitic and stearic acids were greater and the concentration of linoleic acid was less than the corresponding concentrations of these fatty acids in the triglycerides of the adipose tissues.

The effects of the various dietary treatments on the fatty acid composition of the liver triglycerides differed somewhat from the effects of the different diets on the fatty acid compositions of the triglycerides in the plasma and adipose tissues. For instance when the maize oil in the diet given to the rabbits in group I was replaced by an isocaloric amount of butterfat (group 2) or starch (group 4) the decrease in level of linoleic acid in the triglycerides of the plasma and adipose tissues was counterbalanced mainly by the increase in level of palmitic acid, but in the liver triglycerides the decrease in level of linoleic acid was counterbalanced by increases in levels of both palmitic and oleic acids. In the two groups of rabbits given low-fat diets (groups 4 and 6) the fatty acid composition of the liver triglycerides was almost identical with that of the plasma triglycerides. Similar findings have been reported by Swell et al. (I96r) for the serum and liver triglycerides of rabbits given diets containing about $2.5 \%$ fat. The inclusion of fat in the diets given to the rabbits resulted in certain differences between the fatty acid composition of the liver and plasma triglycerides. In the groups of rabbits given the diets containing $10 \%$ (group 5 ) or $20 \%$ (groups $\mathrm{I}, 2,3$ ) fat the concentration of stearic acid in the plasma triglycerides was greater than that in the liver triglycerides. In groups $x, 2$ and 3 the concentration of palmitic acid in the liver triglycerides was greater than that in the plasma triglycerides, and in those groups given diets containing $10 \%$ (groups 3 and 5 ) or $20 \%$ (group r) maize oil the concentration of linoleic acid in the liver triglycerides was greater but the concentration of oleic acid was lower than the corresponding concentrations of these acids in the plasma triglycerides. 


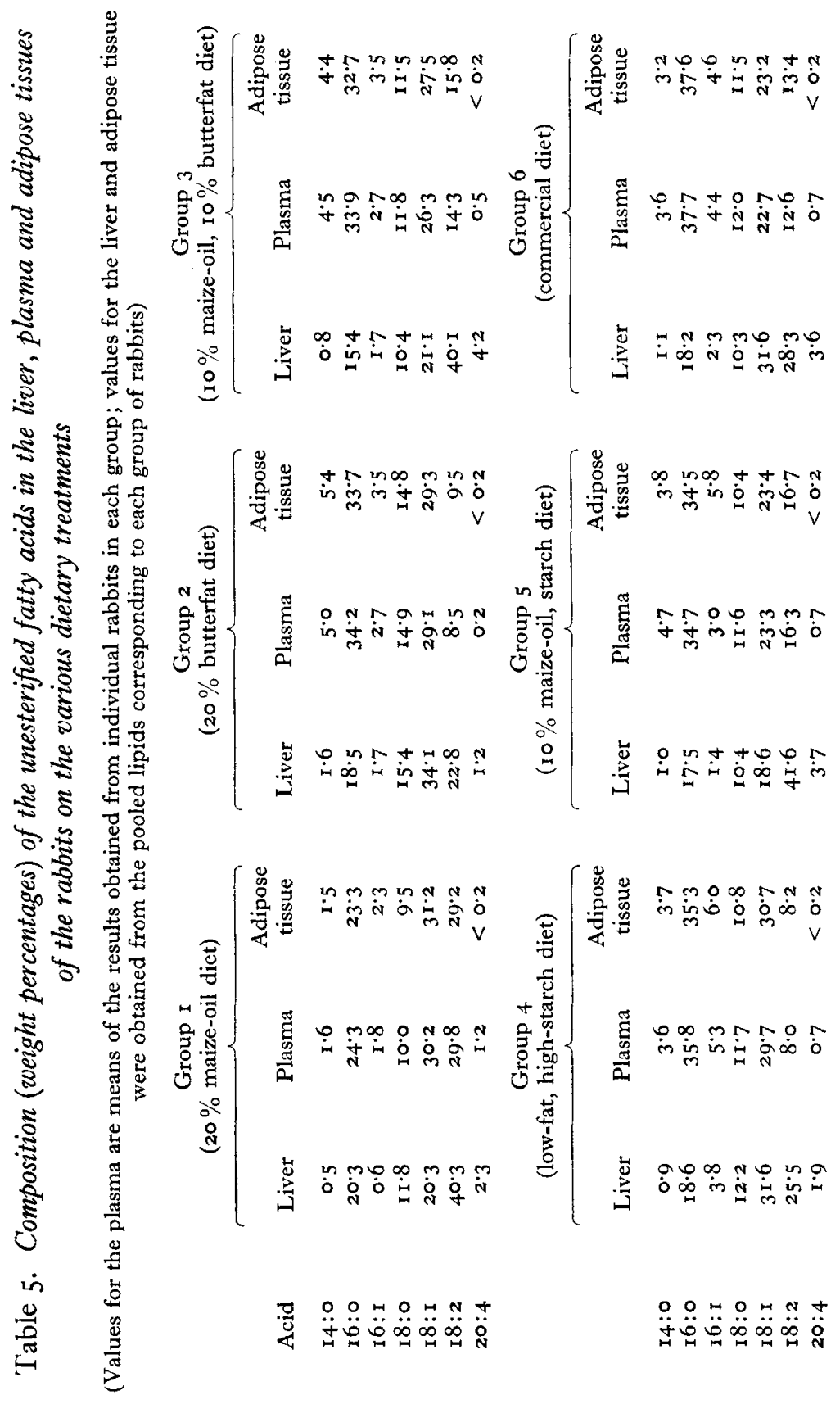


The compositions of the unesterified fatty acids isolated from the pooled livers and pooled adipose tissues from each group of rabbits are given in Table 5. Again, to facilitate comparison, the mean compositions of the unesterified fatty acids in the plasma of each group of rabbits are also given in Table 5. In the liver and adipose tissues of the rabbit, the unesterified fatty acids constituted only about $\mathrm{r} \%$ of the total lipids, but in the plasma they constituted about $5 \%$ (Moore \& Williams, 1963 , $1964 b)$. It is important to note that in each of the six groups of rabbits the composition of the unesterified fatty acids in the plasma was virtually identical with that of the unesterified fatty acids in the adipose tissue. In the unesterified fatty acids of the liver, on the other hand, the concentrations of linoleic and arachidonic acids were consistently greater and the concentrations of myristic, palmitic and palmitoleic acids were consistently less than the corresponding concentrations of these acids in the unesterified fatty acids of the plasma and adipose tissues. The effects of the various diets on the compositions of the unesterified fatty acids of the liver differed from their effects on the compositions of the unesterified fatty acids in the plasma and adipose tissues. This difference in effect of diet on the composition of the unesterified fatty acids of the various tissues was somewhat similar to that already observed for the effect of diet on the composition of the tissue triglycerides (Table 4). Thus, when the maize oil in the diet given to the rabbits in group I was replaced by an isocaloric amount of butterfat (group 2) or starch (group 4) the decrease in level of linoleic acid in the unesterified fatty acids of the plasma and adipose tissues was counterblanced mainly by the increase in level of palmitic acid, but in the unesterified fatty acids of the liver the decrease in level of linoleic acid was counterbalanced almost entirely by the increase in level of oleic acid. It was unexpected to find that the concentration of linoleic acid in the unesterified fatty acids of the liver was not decreased when the content of maize oil in the diet was decreased from $20 \%$ (group I) to $10 \%$ (groups 3 and 5 ).

Comparison of the results given in Tables 4 and 5 shows that, in the unesterified fatty acids isolated from the adipose tissues of each group of rabbits, the concentrations of palmitic and stearic acids were somewhat higher and the concentration of linoleic acid was lower than the corresponding concentrations of these acids in the adipose tissue triglycerides. In the unesterified fatty acids isolated from the livers of each group of rabbits the concentration of palmitic acid was less and the concentration of stearic acid greater than the corresponding concentrations of these acids in the liver triglycerides. With the exception of the rabbits in group I, the concentration of linoleic acid in the unesterified fatty acids of the liver was greater than that in the liver triglycerides. In the groups of rabbits given diets containing 1o or $20 \%$ butterfat (i.e. groups 3 and 2 respectively) the concentration of myristic acid in the liver triglycerides was noticeably greater than that in the unesterified fatty acids of the liver. 


\section{DISCUSSION}

The experiments of Schoenheimer \& Rittenberg (1936) led to the realization that depot fat exists in a state of dynamic equilibrium with other body fat and that, even when there is no net gain or net loss of depot fat, the synthesis and degradation of adipose tissue triglycerides occur continuously. Net mobilization of depot fat occurs when the rate of degradation of adipose tissue triglycerides is greater than the rate of synthesis. On the other hand, net deposition of triglycerides in adipose tissue occurs when the rate of synthesis is greater than the rate of degradation. It has now been firmly established that adipose tissue triglycerides are derived mainly from the triglycerides that circulate as chylomicrons and lipoproteins in the blood stream (Bragdon \& Gordon, 1958; Rodbell, 1960; Bezman, Felts \& Havel, 1962). As regards the mobilization of depot fat, there is general agreement that this process involves the hydrolysis of triglycerides in the adipose tissues and the liberation of the resulting unesterified fatty acids into the blood stream where they are transported in the form of a complex with albumin (Fredrickson \& Gordon, 1958). There is no evidence that lipids are discharged from adipose tissues in any form other than unesterified fatty acids, and adipose tissue triglycerides appear to be the major source of the plasma unesterified fatty acids (Engel, 1962). It might have been expected therefore that, for each group of rabbits in the experiment now reported, the compositions of the plasma unesterified fatty acids would have been identical with the fatty acid compositions of the triglycerides in the plasma and adipose tissues. There was an overall similarity, but in the plasma unesterified fatty acids the concentrations of palmitic and stearic acids were greater and the concentration of linoleic acid was less than the corresponding concentrations of these acids in the adipose tissue triglycerides (Tables 4 and 5). In the adipose tissue triglycerides, the concentrations of palmitic and stearic acids were less and the concentration of linoleic acid was greater than the corresponding concentrations of these acids in the plasma triglycerides. These differences, although small in some instances, appeared consistently in all six groups of rabbits and suggest some selectivity in the incorporation of the fatty acids of the plasma triglycerides into the adipose tissue triglycerides and in the formation of the plasma unesterified fatty acids from the adipose tissue triglycerides. There seems little doubt that at some stage in the uptake of triglycerides from the blood into adipose tissues, the triglycerides are hydrolysed to glycerol and fatty acids (Vaughan \& Korn, I962; Markscheid \& Shafrir, 1965). In the presence of adenosine-5'-triphosphate and coenzyme A, the fatty acids may then be utilized for the synthesis in the adipose tissues of new triglyceride molecules by the pathway that involves $\alpha$-glycerophosphate as an intermediate (Steinberg, Vaughan, Margolis \& Karmen, 1960). It should be noted that since adipose tissue contains no glycerophosphokinase (Wieland \& Suyter, 1957; Margolis \& Vaughan, 1962), the glycerol formed from the hydrolysis of the triglycerides entering the adipose tissue from the blood cannot be utilized for the synthesis of $\alpha$-glycerophosphate which must therefore be derived from blood glucose or adipose tissue glycogen (Raben \& Hollenberg, I960; Bally, Cahill, Leboeuf $\&$ Renold, I960; Steinberg, Vaughan \& Margolis, 1960). The glycerol formed from the 
hydrolysis of the triglycerides in adipose tissues is probably liberated into the blood stream (Hagen, 1963). These metabolic relationships between the triglycerides and unesterified fatty acids in the blood and adipose tissues are shown diagrammatically in Fig. 2. If there are differences in the fatty acid compositions of the triglycerides associated with the various classes of plasma lipoproteins, then any differences that might occur between the fatty acid compositions of the plasma and adipose tissue triglycerides could be explained if the uptake of triglycerides by the adipose tissue is more efficient from certain classes of plasma lipoproteins than from others. However, there would appear to be little difference in the distribution of fatty acids between the

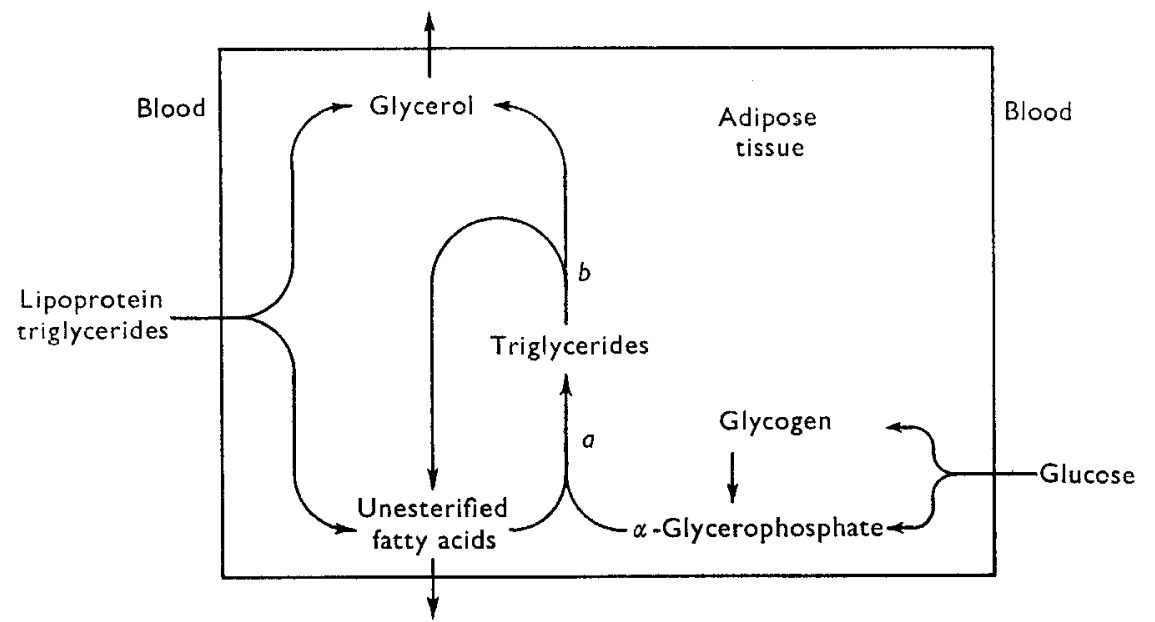

Fig. 2. Metabolic relationships between the triglycerides and unesterified fatty acids in the blood and adipose tissues (references to papers in which these pathways are discussed will be found throughout the text).

triglycerides contained in the various plasma lipoproteins (Freeman, Lindgren \& Nichols, 1963), and experiments in vitro with rat adipose tissue by Markscheid \& Shafrir (1965) have shown that there are no differences in the uptake of triglycerides from different classes of lipoproteins. A possible explanation of the observed differences in the distribution of the various fatty acids between the triglyceride and unesterified fatty acid fractions of the plasma and adipose tissues of the experimental rabbits (Tables 4 and 5) is that in the adipose tissues the enzyme system concerned with the synthesis of triglycerides from fatty acids and $\alpha$-glycerophosphate (Fig. 2, step $a$ ) has a somewhat higher specificity towards linoleic acid than towards stearic and palmitic acids. A second possibility is that the mechanism of the hydrolysis of adipose tissue triglycerides (Fig. 2, step $b$ ) is such that linoleic acid is liberated somewhat less readily than are stearic and palmitic acids. The operation of either or both of these partially selective mechanisms would result in a decrease in the concentration of linoleic acid and increases in the concentrations of stearic and palmitic acids in the unesterified fatty acid fraction and an increase in the concentration of linoleic acid and a decrease in the concentrations of stearic and palmitic acids in the triglyceride fraction of the adipose tissues. The fact that in each group of rabbits the composition of the un- 
esterified fatty acids in the plasma was almost identical with that of the unesterified fatty acids in the adipose tissues (Table 5) supports the contention that the plasma unesterified fatty acids are derived directly from the pool of unesterified fatty acids in the adipose tissues.

Unesterified fatty acids may be taken up from the blood by several tissues such as the heart and liver. In these tissues, the fatty acids may be utilized as a source of energy or for incorporation into more complex lipids. In man, Gordon \& Cherkes (1956) and Gordon (1957) have demonstrated the uptake of unesterified fatty acids by the myocardium and, according to Gordon (I957), the unesterified fatty acids of the blood may function, in the fasting state, as a major source of energy for human heart muscle. Fredrickson \& Gordon (1958) administered ${ }^{14} \mathrm{C}$-labelled fatty acids intravenously to man and found that the labelled fatty acids appeared in the plasma triglycerides. It seems likely from the results of experiments with rats that this conversion takes place in the liver. Thus, Stein \& Shapiro (1959) and Laurell (I959) administered ${ }^{14} \mathrm{C}$-labelled fatty acids intravenously to rats and found that the labelled fatty acids appeared first in the liver triglycerides and then in the plasma triglycerides. From experiments with man, Friedberg, Klein, Trout, Bogdonoff \& Estes (196I) have concluded that the major fraction of the fasting plasma triglycerides is derived from the unesterified fatty acids of the plasma. Nestel \& Steinberg (1963) have shown that there is some selectivity in the incorporation of different unesterified fatty acids into the triglycerides of rat liver. When rat livers were perfused with fluid containing palmitic acid the concentration of palmitic acid in the liver triglycerides increased from 23 to $47 \%$, but when the livers were perfused with fluid containing linoleic acid the concentration of linoleic acid in the liver triglycerides increased from $3^{2}$ to only $37 \%$. If such a selective process operates in the liver of the rabbit then it seems reasonable to suppose that, of the unesterified fatty acids that are taken up by the liver from the blood, palmitic acid would be preferentially utilized for the synthesis of liver triglycerides. Hence, the pool of unesterified fatty acids in the liver would be rapidly depleted of palmitic acid. Support for this contention is provided by the results of the experiment now reported. In all six groups of rabbits, the concentration of palmitic acid in the plasma unesterified fatty acids was consistently greater than that in the liver unesterified fatty acids and the concentration of palmitic acid in the liver triglycerides was consistently greater than that in the liver unesterified fatty acids (Tables 4 and 5). In each group of rabbits the concentration of palmitic acid in the liver triglycerides was very similar to that in the plasma unesterified fatty acids (Tables 4 and 5). The finding that the concentrations of linoleic and arachidonic acids in the unesterified fatty acid fractions of the liver were consistently greater than the corresponding concentrations of these acids in the unesterified fatty acid fraction of the plasma (Table 5) may be due to the fact that the pool of unesterified fatty acids in the liver was to some extent supplemented by fatty acids derived from the breakdown of phospholipids in the liver. Liver phospholipids undergo continual metabolic turnover and are relatively rich sources of linoleic and arachidonic acids (Moore \& Williams, 1963 , 1965)

In an animal given a low-fat diet, the constituent fatty acids of the liver trigly- 
cerides are derived first from the fatty acids that are synthesized de novo from acetyl coenzyme $\mathrm{A}$ in the hepatic tissues and second from that fraction of the plasma unesterified fatty acids that is taken up by the liver. There is considerable evidence that, under these conditions, the liver is the major source of the triglycerides that circulate in the blood (Stein \& Shapiro, 1959; Byers \& Friedman, 1960; Kay \& Entenman, 196r; Borgström \& Olivecrona, 196ı; Havel \& Goldfien, 1961). It was not surprising therefore to find that in each of the two groups of rabbits given the low-fat diets (groups 4 and 6 ) the fatty acid composition of the liver triglycerides was almost identical with that of the plasma triglycerides (Table 4). Differences between the fatty acid compositions of the plasma and liver triglycerides were small in the rabbits of group 5 (given the diet containing $10 \%$ fat), but were more noticeable in the rabbits of groups I, 2 and 3 (given diets containing $20 \%$ fat). After absorption from the small intestine, long-chain fatty acids of dietary origin enter the blood primarily as triglycerides that are transported in the form of chylomicrons. These chylomicrons may then be taken up by the liver from the blood stream (Borgström \& Jordan, 1959). In the study now reported, the rabbits had access to food up to the time that the blood samples were taken, so it seems likely that, in the animals given the high-fat diets, the plasma and liver triglycerides would have been derived from both endogenous and exogenous sources. In rabbits given high-fat diets it is reasonable to suppose therefore that any differences between the fatty acid compositions of the liver and blood triglycerides might be explained in terms of the differences that may occur in the proportions of exogenous and endogenous triglycerides that are present in the liver and blood.

The authors gratefully acknowledge the encouragement and advice given by Professor S. K. Kon, and thank Mr D. R. Westgarth for guidance on the statistical analysis of the results and Miss J. Carrinci for skilled technical assistance. This study was supported by a grant from the Butter Information Council.

\section{REFERENCES}

Albrink, M. J. (1 959). F. Lipid Res. I, 53.

Arvidson, G. \& Olivecrona, T. ( ( 962). Acta physiol. scand. 55, $3 \circ 3$.

Bally, P. R., Cahill, G. F. Jr., Leboeuf, B. \& Renold, A. E. (I960). F. biol. Chem. 235, 333.

Bezman, A., Felts, J. M. \& Havel, R. J. (1962). F. Lipid Res. 3, 427.

Borgström, B. \& Jordan, P. (1959). Acta Soc. Med. upsal. 64, 185.

Borgström, B. \& Olivecrona, T. (1961). F. Lipid Res. 2, 263.

Bragdon, J. H. \& Gordon, R. S. Jr. (1958). F. clin. Invest. 37, 574.

Byers, S. O. \& Friedman, M. (1960). Am. F. Physiol. 198, 629.

Carroll, K. K. (1961). F. Lipid Res, 2, 135.

Duncan, D. B. (1955). Biometrics, XI, I.

Engel, F. L. (1962). In Adipose Tissue as an Organ, p. 126. [L. W. Kinsell, editor.] Springfield, Ill.: C. C. Thomas.

Farquhar, J. W., Insull, W. Jr., Rosen, P., Stoffel, W. \& Ahrens, E. H. Jr. (1959). Nutr. Rev. 17, Suppl. Folch, J., Lees, M. \& Stanley, G. H. S. (I957). J. biol. Chem. 226, 497.

Freeman, N. K., Lindgren, F. T. \& Nichols, A. V. (1963). In Progress in the Chemistry of Fats and Other Lipids. Vol. 6, p. 216. [R. T. Holman, W. O. Lundberg \& T. Malkin, editors.] Oxford: Pergamon Press.

Fredrickson, D. S. \& Gordon, R. S. Jr. (1958). Physiol. Rev. 38, 585. 
Friedberg, S. J., Klein, R. F., Trout, D. L., Bogdonoff, M. D. \& Estes, E. H. Jr. (196r). F. clin. Invest. 40, 1846 .

Gordon, R. S. Jr. (1957). F. clin. Invest. 36, 810.

Gordon, R. S. Jr. \& Cherkes, A. (1956). F. clin. Invest. 35, 206.

Hagen, J. H. (1963). Biochem. Soc. Symp. no. 24, p. 159.

Havel, R. J. \& Goldfien, A. (1961). F. Lipid Res. 2, 389.

Hirsch, J., Farquhar, J. W., Ahrens, E. H. Jr., Peterson, M. L. \& Stoffel, W. (rg60). Am. F. clin. Nutr. $8,499$.

Kay, R. E. \& Entenman, C. (1961). F. biol. Chem. 236, 1006.

Kramer, Y. K. (1956). Biometrics, 12, 307.

Laurell, S. (1959). Acta physiol. scand. 47, 218.

Margolis, S. \& Vaughan, M. (1962). F. biol. Chem. 237, 44.

Markscheid, L. \& Shafrir, E. (1965). F. Lipid Res. 6, 247.

Moore, J. H. (1962). f. Dairy Res. 29, 141.

Moore, J. H. \& Williams, D. L. (1963). Can. F. Biochem. Physiol. 4r, I82 r.

Moore, J. H. \& Williams, D. L. (1964a). Br. F. Nutr. 18, 253.

Moore, J. H. \& Williams, D. L. (1964b). Br. F. Nutr. I8, 43 I.

Moore, J. H. \& Williams, D. L. (1964c). Br. F. Nutr. 18, 603.

Moore, J. H. \& Williams, D. L. (1964d). Biochim. biophys. Acta, 84, 41.

Moore, J. H. \& Williams, D. L. (1965). Br. J. Nutr. 19, 407.

Nelson, G. J. \& Freeman, N. K. (1959). F. biol. Chem. 234, I375.

Nestel, P. J. \& Steinberg, D. (1963). F. Lipid Res. 4, 46r.

Raben, M. S. \& Hollenberg, C. H. (I g6o). F. clin. Invest. 39, 435.

Rodbell, M. (1 960). F. biol. Chem. 235, I6r3.

Schoenheimer, R. \& Rittenberg, D. (1936). F. biol. Chem. II4, 381 .

Schrade, W., Biegler, R. \& Böhle, E. (196r). F. Atheroscler. Res. x, 47.

Stein, Y. \& Shapiro, B. (1959). Am. F. Physiol. 196, I238.

Steinberg, D., Vaughan, M. \& Margolis, S. (r96o). \%. biol. Chem. 235, PC 38.

Steinberg, D., Vaughan, M., Margolis, S. \& Karmen, A. (1 960). Fedn Proc. Fedn Am. Socs exp. Biol. I9, 227.

Swell, L., Law, M. D., Schools, P. E. \& Treadwell, C. R. (r96r). Y. Nutr. 75, I8I.

Vaughan, M. \& Korn, E. D. (1962). In Adipose Tissue as an Organ, p. 173. [L. W. Kinsell, editor.] Springfield, I1l.: C. C. Thomas.

Wieland, O. \& Suyter, M. (1957). Biochem. Z. 329, 320. 